\title{
Gelation, Shear-Thinning and Shear-Thickening in Cement Slurries
}

\author{
D. Lootens ${ }^{1,2}$, P. Hébraud ${ }^{2}$, E. Lécolier ${ }^{1}$ and H. Van Damme ${ }^{2}$ \\ 1 Institut français du pétrole, Division Chimie et physicochimie appliquées, 1 et 4, avenue de Bois-Préau, 92852 Rueil-Malmaison Cedex - France \\ 2 ESPCl, Physicochimie des polymères et des milieux dispersés, UMR CNRS 7615, 10, rue Vauquelin, 75231 Paris Cedex 05 - France \\ e-mails: didier.lootens@espci.fr - eric.lecolier@ifp.fr - pascal.hebraud@espci.fr - henri.vandamme@espci.fr
}

Résumé - Coagulation, rhéofluidification et rhéoépaississement dans les coulis de ciment — Le comportement rhéologique des coulis de ciment peut se décliner en plusieurs comportements élémentaires :

- la formation rapide d'un gel faible au repos ;

- l'effondrement de ce gel sous une contrainte critique directement liée à l'intensité des forces interparticulaires ;

- la destruction progressive des fragments de ce gel sous cisaillement modéré, avec un comportement d'autant plus rhéofluidifiant que la taille des grains élémentaires est faible ;

- la reformation, d'abord transitoire puis continue, à fort gradient de vitesse, de structures résistant au cisaillement, probablement sous forme de chaînes de grains au contact avec, sur le plan rhéologique, l'apparition d'un rhéoépaississement ;

- éventuellement, le blocage de l'écoulement.

Nous démontrons les mécanismes de passage d'un état au suivant. Nous montrons comment l'addition d'agents dispersants favorise l'état rhéoépaississant au détriment de l'état rhéofluidifiant et comment le contrôle de l'état de surface des grains et du frottement intergranulaire permet de limiter le rhéoépaississement et les risques de blocage.

\footnotetext{
Abstract-Gelation, Shear-Thinning and Shear-Thickening in Cement Slurries - The rheological behavior of cement slurries may be described in terms of a few elementary behaviors:

- the rapid formation of a gel, at rest;

- the collapse of this gel under a critical stress directly related to the strength of the interparticle forces;

- the progressive destruction of the gel fragments under moderate shear rate, with an increasingly shear-thinning behavior as the elementary particles gets smaller;

- the reconstruction, at high shear rate, of shear-resistant structures, probably as chains of grains at contact;

- complete jamming, possibly.
}

We analyze the transition mechanisms from one step to the next one. We show how the addition of a dispersing agent favors shear-thickening at the expense of shear-thinning and how the control of the particle surface state and of interparticle friction restricts shear-thickening and the risk of jamming. 


\section{INTRODUCTION}

Cement slurries belong to a class of fluids which share with colloidal suspensions their sensitivity to non contact surface forces (van der Waals, double layer) [1] and with granular media their high density and their sensitivity to interparticle contact and to many body interactions $[2,3]$. This confers to cement slurries a particularly complex rheological behavior. Yet, this rheological behavior is of uttermost importance in industrial operations. For example, during an oilwell cementing, carefull control of the rheological properties and flow conditions of the cement slurry is required in order to achieve good mud removal and proper placement of the slurry prior to setting under high pressure and temperature conditions. Mineral formulation and organic admixtures (in particular, the so-called superplasticizers, SP) are essential for this control. Yet, our understanding of subtle molecular differences, but with far reaching rheological consequences, is poor. For instance, why do polynaphthalene sulfonate (PNS) admixtures confer shear-thinning properties to cement slurries in the flow conditions used in practice, and why do polycarboxylate polymers with polyoxyethylene side groups (PCP) induce a shear-thickening behavior to the same slurries in the same conditions? We are still largely disarmed in front of such questions. It is the purpose of this paper, not to analyze the influence of molecular details on the rheological behavior of slurries, but to provide a basis for understanding the important physical parameters at work, both in real and in model systems.

\section{BACKGROUND}

\subsection{Oil Well Cementing [4]}

Rotary drilling is the worldwide method used to drill oil and gas wells. This method consists in the use of a rotating bit which crushes the rock formation, and a continuous drilling fluid injection, which removes the rock cuttings and brings them to the surface. One of the main advantages of the rotary method is that the drilling fluid can be pumped through the bit. Once a section of the well has been drilled, the drill pipe is removed from the hole and a casing pipe is run into the hole until it reaches the bottom. This operation is achieved with the borehole full of drilling fluid. Once the casing pipe is in place, a cement slurry is pumped down into the casing string to the bottom of the well and then flows up through the annulus between the casing and the borehole wall (Fig. 1). This last operation is called primary cementing.

The major goal of the primary cementing is to provide a complete and permanent zonal isolation within the well bore. This means that the cement sheath must prevent any fluid circulation (gas, oil, water, etc.) between different rocks layers. To achieve this objective, the drilling fluid must be

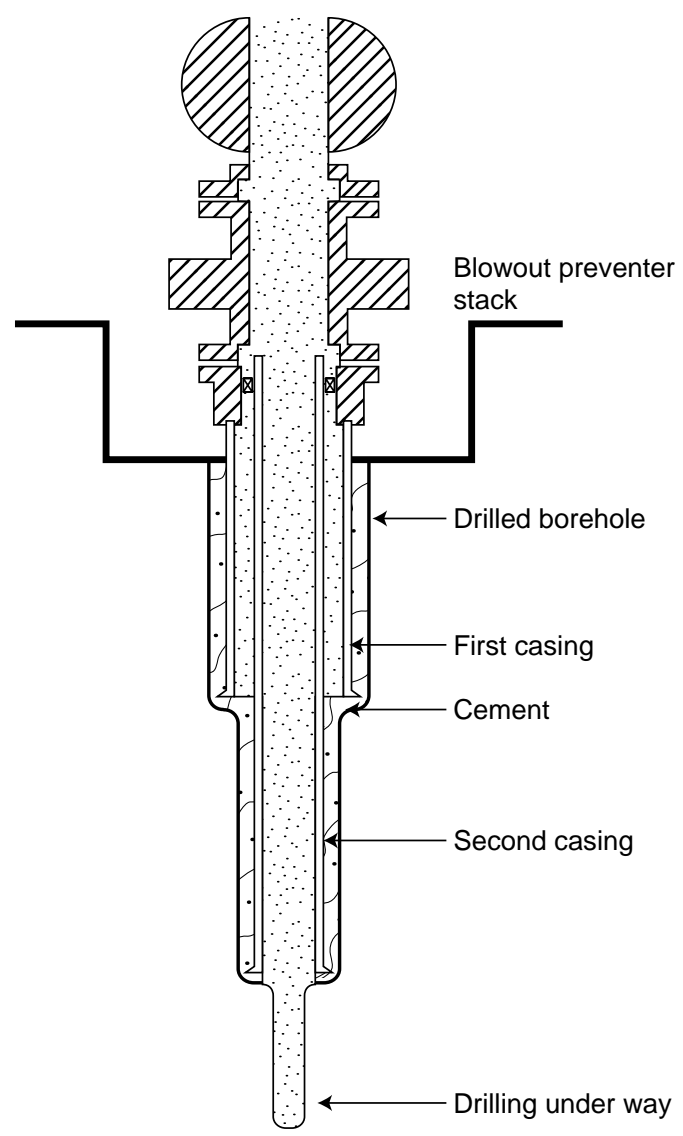

Figure 1

Simplified cross-section of a borehole

removed from the annulus and the cement slurry put in place. Therefore, good mud removal and cement placement are essential to avoid interzonal fluid flows. Incomplete zonal isolation may lead to environment pollution problems or production rates lower than expected. That is why primary cementing is often considered as one of the most important operations performed in a well. Primary cementing also aims at mechanically securing the casing string to the borehole walls and at protecting the casing from corrosion by the fluids contained in the drilled rock formations.

Primary cementing is not the only one cementing operation. Squeeze cementing is a cementing operation performed under pressure to inject cement through perforations in the casing in order to consolidate or repair the primary cementing. In this case, the shear rate experienced by the cement slurry through the perforations is extremely high. Thus, careful cement design, emphasizing flow properties, must be performed to avoid any problem of placement during squeeze cementing.

After 25 years or so, when the production rate becomes very low, the wells have to be plugged. The main aim of well abandonment is to permanently seal the well bore for a geological time scale in order to prevent any leakage of 
formation fluids to surface. Long-term durability of the cement is of paramount importance in this operation. One of the most critical phases during the plug-and-abandon operation is the cement placement. Achieving a proper placement of the different plugs within the wells requires to control the rheological properties of the cement-based slurries.

In every cementing operation, one can see that placement process is of great importance. Improving the placement process of the cement in wells is therefore essential to achieve successful cementing jobs in complex types reservoir such as abnormally high-pressure gas fields or unconsolidated multi-zone reservoir.

\subsection{Cement Hydration [5, 6]}

The mineral mixture used in cementing operations is basically a fine mortar, i.e. a mixture of cement and fine mineral particles like silica fume, with organic admixtures. Cement itself is a mixture of several mineral phases, the most abundant being an impure tricalcium silicate, $3 \mathrm{CaO} \cdot \mathrm{SiO}_{2}$ (alite) and its dicalcium equivalent, $2 \mathrm{CaO} \cdot \mathrm{SiO}_{2}$ (belite). Oil well cements are particularly rich in silicate phases. According to American Petroleum Institute standards, tricalcium aluminate content of a class $\mathrm{G}$ cement must be lower than $3 \%$. When cement is mixed with water, it undergoes a dissolution reaction generating, among others, calcium, silicate and aluminate ions in the interstitial solution. After a few hours, new products called "hydrates" precipitate, the most important being calcium-silicate-hydrate $(\mathrm{C}-\mathrm{S}-\mathrm{H})$ and calcium hydroxyde (portlandite). This dissolution-diffusionprecipitation process yields a geometrically complex interface between the anhydrous silicate and $\mathrm{C}-\mathrm{S}-\mathrm{H}$ on one hand and between the hydrates and the solution on the other hand. As the hydration reaction proceeds, more and more anhydrous material is converted into hydrates, with an overall decrease of the porosity since the volume of hydrates produced by the thorough reaction of tricalcium silicate with water is more than twice the initial anhydrous volume [7].

Two important mechanical events occur during hydration [8]. The first one is a simple gelation of the slurry, due to the high ionic strength of the aqueous phase [9-11]. It occurs quasi immediately after mixing the cement with water, at virtually zero hydration. The coagulated network has a poor mechanical strength. It may be easily destroyed, by mixing for instance. It is nevertheless strong enough to give the slurry a measurable yield stress for flow. The second and more important event is setting, which starts a few hours after coagulation. The period between coagulation and setting is (improperly) called the dormant period. In fact, hydrate particles nucleation is occurring, followed by growth [12]. A continuous reinforcement process is going on in contact areas, leading, at some point, to mechanical percolation (setting). At this point, the shear modulus is in the GPa range.
However, only a few percent of the anhydrous cement have been transformed into hydrates at this point [13]. Further hydration and (ill understood) long term redistribution of matter and voids [14] lead to further reinforcement, over periods of weeks, months or even years.

In the present paper, we will focus on the rheological properties of the cement slurries in the dormant period, when the slurry is able to be pumped. In static conditions (slurry at rest), we will concentrate on gel formation and on its measurement by nondestructive ultrasonic techniques. The gel strength of cement slurries is a critical property for pressure transmission in the well, for gas migration control and for efficient mud removal [4]. In dynamic conditions (slurry under flow), we will concentrate on the shear rate dependence of viscosity, which is critical for pumping. As will be shown, depending on the shear rate, and on the flocculation or gelation state of the slurry and also on the surface state of the particles, shear-thinning or shearthickening may be observed. The influence of organic admixtures (superplasticizers) will be exemplified.

\section{EXPERIMENTAL}

\subsection{Materials}

Experiments on cement slurries were performed with a silicarich Portland cement. No other particles were added. The superplasticizer which was used in some cases is an acrylatebased polyelectrolyte with polyoxyethylene (POE) side chains. As model system, we used suspensions of silica particles synthesized by a Stöber-type method [15]. Monodisperse spherical particles were prepared, with diameters from $100 \mathrm{~nm}$ to $2.5 \mu \mathrm{m}$ (Fig. 2).

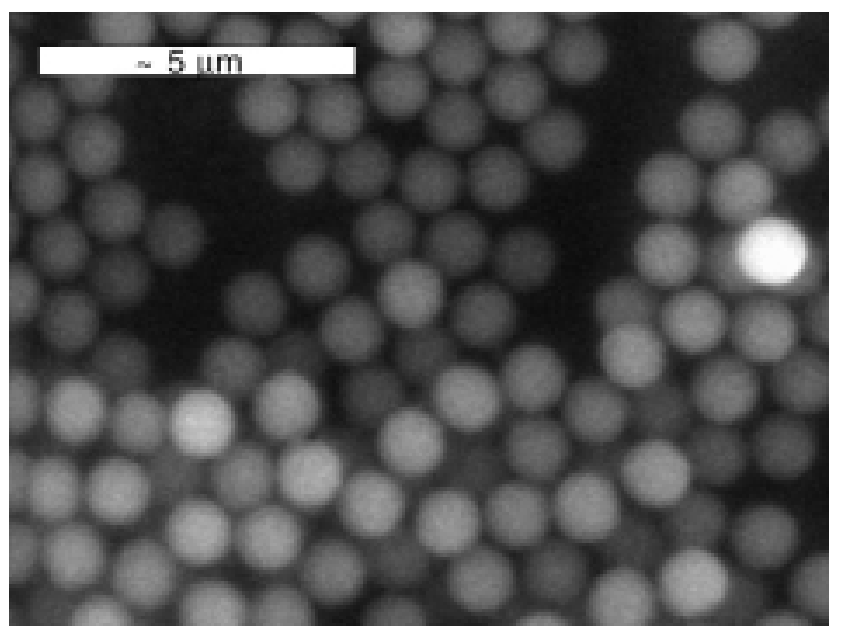

Figure 2

Sample of monodisperse silica spheres $(1.5 \mu \mathrm{m})$ observed with a scanning electron microscope. 


\subsection{Rheological Measurements}

A stress-controlled AR1000 instrument from TA Instrument was used, with several shearing tools. For shear modulus measurements in oscillating conditions, a ribbon geometry was used [16], with an equivalent Couette radius of $6.8 \mathrm{~mm}$ and a height of $20 \mathrm{~mm}$, in a cylindrical vessel of $10 \mathrm{~mm}$ internal radius. The main advantage of this unconventional geometry is that it allows for mixing ( $30 \mathrm{~s}$ ) the slurry directly in the measuring vessel prior to starting the measurement. The system was calibrated using three different Newtonian oils, covering three orders of magnitude in viscosity. For viscosity measurements in continuous shear conditions, a RFSII instrument from Rheometrics with a Couette geometry was used (17.5 mm outer diameter; $0.25 \mathrm{~mm}$ gap). Alternatively, for normal stress difference measurements, a plateplate geometry was used (50 $\mathrm{mm}$ diameter).

\subsection{Ultrasonic Measurements}

The ultrasonic spectrometer used to measure the shear and compression modulus is similar to previously described devices operating in the reflection mode [17, 18]. Basically, the systems follows the temporal evolution of a broad band pulse $(1 \mathrm{MHz})$ generated by an emitter/receiver transducer, traveling through a Plexiglas delay line and reflected at the Plexiglas/paste interface. The simultaneous measurement of the reflection coefficient of longitudinal and transverse waves allows for the determination of the complex Young, shear and bulk moduli, $E^{*}, G^{*}$ and $K^{*}$, respectively.

\section{CEMENT SLURRIES}

\subsection{Static Structure Formation and Gel Strength}

Figure 3 illustrates the time evolution of the complex bulk and shear modulus of a cement paste prepared at a water/cement ration of 0.8 . Whilst $K^{*}$ undergoes little change before setting at $t \cong 2 \times 10^{4} \mathrm{~s}, G^{*}$ shows two clear jumps. The first one, with a rise of more than two decades over the background noise, is the clear signature of gelation. Remarkably, it occurs in a very short time window, from a few seconds to a few minutes after mixing cement and water. This gelation jump is followed by a well defined plateau corresponding to the so called dormant period. The second jump, much better resolved with $G^{*}$ than with $K^{*}$, corresponds to setting and amounts to about two decades, from $\sim 10^{7}$ to $\sim 10^{9} \mathrm{~Pa}$.

As shown in Figure 4 for $G^{*}$, the gelation jump and the plateau value which follows are much better defined with ultrasonic methods than with rheometrical techniques. A first possible parameter to consider for this is the much higher measuring frequency of the ultrasonic probe $(1 \mathrm{MHz})$ compared to the rheometrical tool $(1 \mathrm{~Hz})$. Long time relaxation processes that would not exist in model gel networks could be responsible for the higher measured elastic modulus at high frequencies. Another factor to consider is the very limited linear viscoelastic domain of cement pastes. Estimates for this using oscillatory shear measurements point to a linear strain limit of the order of $10^{-4}[19,20]$. This is very small and close to the sensitivity

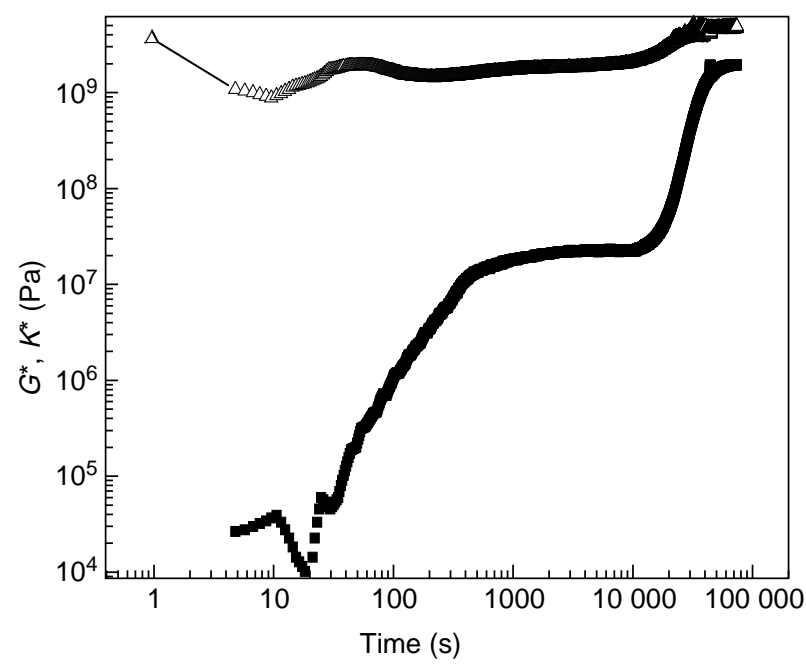

Figure 3

Evolution of the complex bulk $\left(K^{*}\right)$ and shear $\left(G^{*}\right)$ moduli (upper and lower curve, respectively) of a cement slurry, prepared at water/cement $=0.8, \mathrm{w} / \mathrm{w}$, as a function of time after mixing. The ultrasonic method was used (see text).

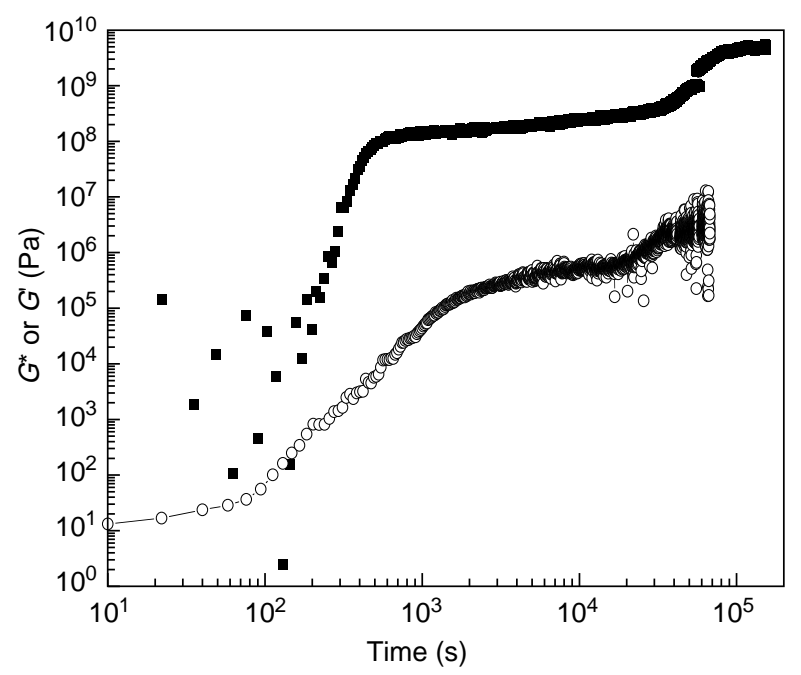

Figure 4

Time evolution of the complex shear modulus, $G^{*}$ and elastic shear modulus, $G^{\prime}$ of a cement slurry prepared at water/ cement $=0.35, \mathrm{w} / \mathrm{w}$, as measured respectively by ultrasonic and rheometrical method (upper and lower curve, respectively). 


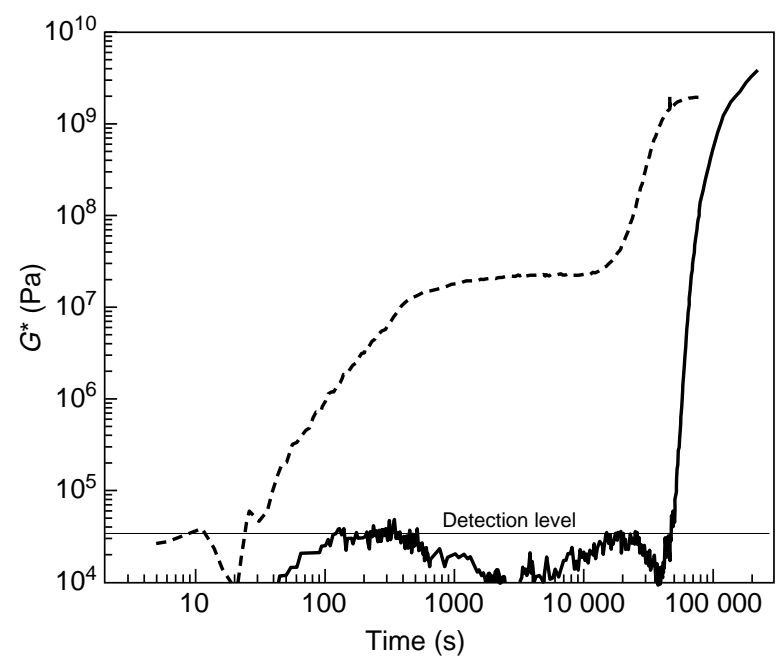

Figure 5

Time evolution of the complex shear modulus, $G^{*}$, of a cement slurry prepared at water/cement $=0.80 \mathrm{w} / \mathrm{w}$, without and with addition $(0.18 \% \mathrm{w} / \mathrm{w} \mathrm{SP} / \mathrm{cement})$ of acrylic superplasticizer (upper and lower curve, respectively). The horizontal line indicates the minimum significant detection level. Notice the retarding effect of the SP on setting.

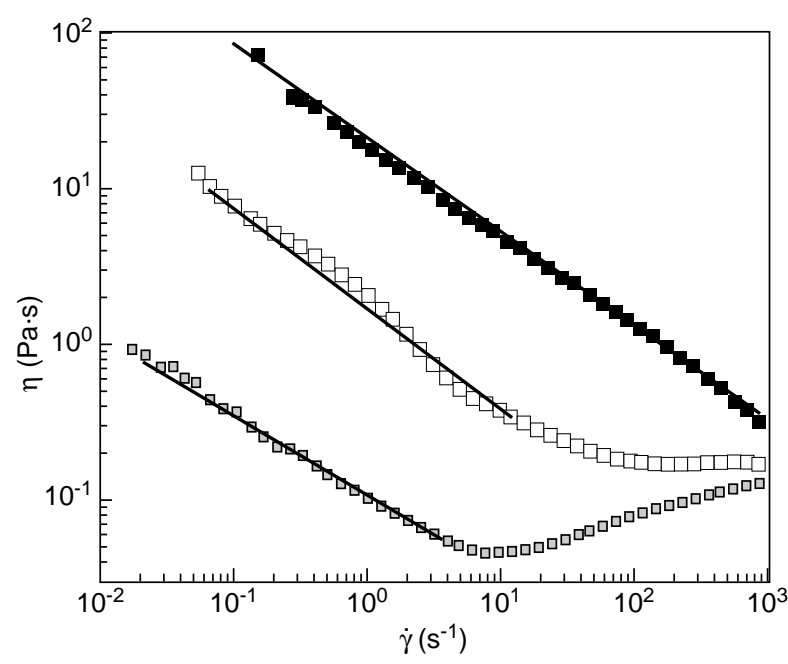

Figure 6

Viscosity as a function of shear rate for cement slurries prepared without (upper curve, $\phi=0.45$ ) or with increasing amounts of acrylic superplasticizer $(\phi=0.51$ and SP/cement $=0.2$ and $0.4 \% \mathrm{w} / \mathrm{w}$ for the middle and lower curve, respectively). limit of most rheometers, but it is far above the extremely small strains induced by the ultrasonic transducer. Thus, it might well be that even the smallest strains applied to cement paste samples in rheometers are somewhat within the non linear domain and lead to some underestimation of the linear modulus. This does not happen with ultrasonic excitation.

What this single experiment shows is that the build up of the hardened cement microstructure is not the sole fact of hydrate precipitation and setting. The very rapid increase of ionic strength occurring as soon as the cement is contacted with water induces, if no superplasticizer is added, a coagulation process which leads to a weak gel. To what extent the final material keeps the memory of this initial structure will depend on the many events of its life. Basically, it will depend on the kinetics of its destruction under shear and on the kinetics of its reconstruction once the flow has stopped. Of course, addition of the right amount of a superplasticizer with efficient dispersing properties prevents gelation from occurring. In this case, the only modulus jump observed is the second one associated with setting (Fig. 5).

\subsection{From Shear-Thinning to Shear-Thickening}

It is clear from the previous section that, if no dispersing agent is added, a cement slurry is a flocculated system which is expected to be broken up into smaller units under shear. In rheological terms, this is shear-thinning. It is illustrated in Figure 6 for a cement slurry with a solid volume fraction $\phi=0.45$. The apparent viscosity decays according to a power law $\eta \propto \dot{\gamma}^{-\alpha}$ with $\alpha \cong 0.5$ over more than four decades in shear rate.

Addition of a dispersing acrylic polyelectrolyte modifies this behavior in two ways (Fig. 6). A first trivial effect is the lowering of the viscosity level, which may be assigned to the deflocculating action of the additive and the decrease of the overall connectivity of the medium. The second point, less trivial, is that shear-thinning is still observed, but only in a low shear rate domain. Beyond a critical shear rate, the system now becomes shear-thickening. Moreover, the better dispersed the system, the lower the critical shear rate for the onset of shear-thickening (Fig. 6). It should be noted that strong shear-thickening unavoidably leads to slip at the pastetool interface, even with rough surfaces. Therefore, the transition from shear-thinning to shear-thickening as illustrated in Figure 6 is probably smoother than the real transition. Shearthickening has been observed in many systems, including crushed quartz sand slurries and cement slurries [21]. Considering the relatively low shear rate at which it starts with commonly used superplasticizer loadings $\left(\sim 10 \mathrm{~s}^{-1}\right.$ at $\sim 0.4 \%$ w/w SP/cement, Fig. O), it is not without importance for cement slurry flow in the annulus of an oil well.

The mechanism of shear-thickening is still a matter of debate. It has been assigned either to an order-disorder transition or to the formation of force chains [22]. Numerical simulations [23] and experimental results [24] on simple dispersions showed that, at high Péclet numbers, when Brownian forces are negligible compared to shearing forces, the pair distribution function of particles become 
asymmetric, with an excess of particle pairs along the compressional axis. Moreover, at high enough volume fractions, the collapse of gaps between particles induces the formation of elongated clusters along the compressional axis of flow [25]. On the other hand, concentration fluctuations lead to an increase of the viscosity [26] and, eventually, to complete jamming of the suspension [27] (flow stops). One may thus assume, by similarity with dry granular materials, that clusters of some sort form force chains which are able to sustain the stress applied along the compressional direction [28]. It implies that, under constant shear rate, strong stress fluctuations associated to formation and rupture of these aggregates should occur. Such stress fluctuations have been observed in dry granular materials [29], with a broad distribution of amplitudes [30]. In concentrated suspensions, a different situation has been observed [31]: as a continuously increasing shear rate is applied, the suspension goes from a low viscosity regime at low shear rate to a high viscosity regime at high shear rate. In the intermediate regime, the stress fluctuates but is bounded by these two branches of flow.

It is difficult, on the basis of the few results reported in this section to elaborate on the shear-thickening mechanism of cement slurries (this will be discussed in the next Sections). Nevertheless, a point which is worth being stressed now is that shear-thickening occurs more clearly (i.e. clear changes of slope in $\eta=f(\dot{\gamma})$ diagrams) and more easily (i.e. at lower stress and lower shear rate) in conditions where the flowing particles are hard particles than in those were the flowing particles are hollow and deformable objects (flocs). We feel that this is an important, yet qualitative, argument in favor of stress transmission by contact forces.

\section{MODEL SYSTEMS}

As shown in the previous Sections, it is easy to show qualitatively that shear-thickening and eventually jamming occurs at high shear rates in well dispersed cement slurries. However, due to the chemically reactive nature of cement, the ill defined particle shape and the broad particle size distribution, cement is not the best suited material to study the jamming transition in detail. This is why we used spherical silica particles with a very narrow size distribution, as described in the next Section. Another interest of silica is that it is easy to limit flocculation by working at low ionic strength and $\mathrm{pH} 9$ (i.e. well above the point of zero charge).

\subsection{A Dynamic Phase Diagram}

When dispersed in water the silica particles also form a gel but, as expected from their surface properties, this gel is much weaker than with cement. Figure 7 illustrates a typical evolution of the storage and loss moduli in stress-controlled oscillatory measurements $(1 \mathrm{~Hz})$. At low stress, the system behavior is that of a gel with a linear viscoelastic domain in which $G^{\prime}>G^{\prime \prime}$. Beyond a critical stress, the suspension starts flowing and $G^{\prime \prime}>G^{\prime \prime}$. We used the crossing point of the $G^{\prime}$ and $G^{\prime \prime}$ curves as the transition stress for the gel-fluid transition. This transition stress is increasing exponentially with the solid volume fraction $\phi$. On the other hand, it is decreasing when larger particles are used (Fig. 8, [32]). In

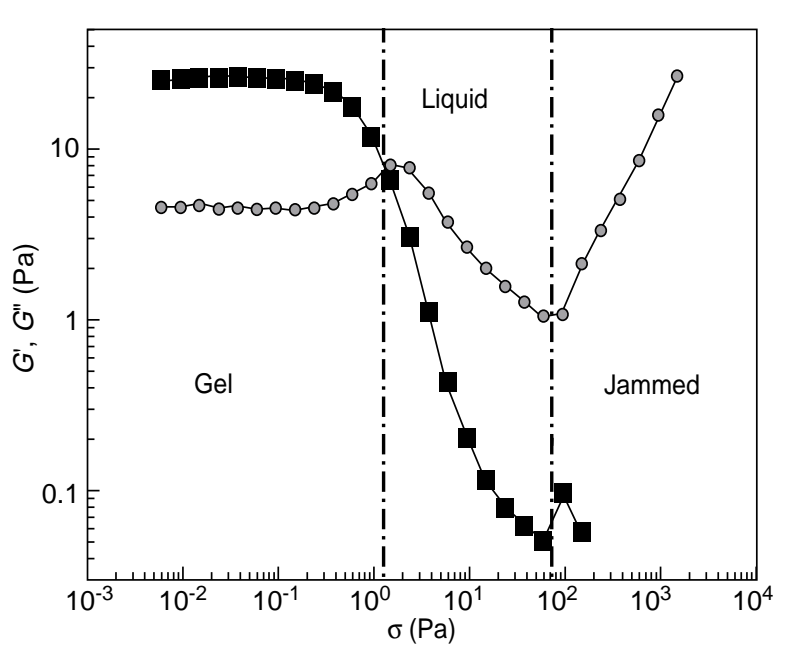

Figure 7

Evolution of the storage $\left(G^{\prime}, \mathbf{\square}\right)$ and loss $\left(G^{\prime \prime}, \boldsymbol{\bullet}\right)$ moduli of a silica slurry (400 nm particles; $\phi=0.422)$ measured by dynamic mode $(1 \mathrm{~Hz})$ stress-controlled rheometry in coneplane geometry, as a function of stress amplitude.

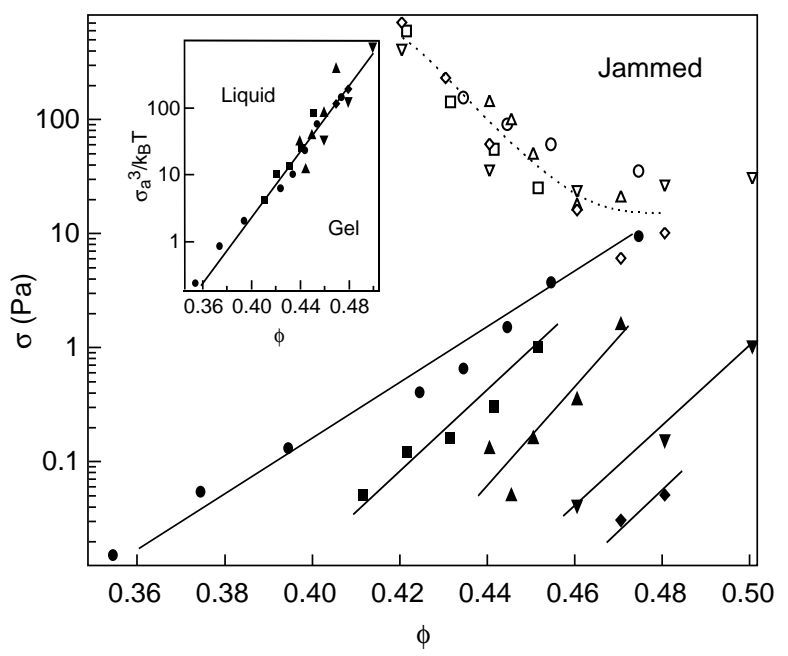

Figure 8

Dynamical phase diagram showing the boundaries between the gel and the fluid state (closed symbols) and between the fluid and the jammed state (open symbols), respectively, for silica suspensions with different particle sizes: $(\bullet, O) 400 \mathrm{~nm}$; $(\boldsymbol{\square}, \square) 700 \mathrm{~nm} ;(\boldsymbol{\Delta}, \Delta) 1 \mu \mathrm{m} ;(\boldsymbol{\nabla}, \nabla) 1.5 \mu \mathrm{m} ;(\diamond, \diamond) 2.5 \mu \mathrm{m}$. Insert: boundary between gel and fluid state, in dimensionless stress units. 
agreement with theory [33], the transition between the gel and fluid state, for a given $\phi$, is always occurring at the same dimensionless stress, $a^{3} \sigma / k_{B} T$, where $a$ is the particle radius and $k_{B} T$ the thermal activation energy (insert of Fig. 8). What this means is that the transition between the gel and the fluid state is governed by interparticular forces.

As the stress is increased further, a second critical stress is reached beyond which a dramatic increase of the loss modulus $G^{\prime \prime}$ is observed (Fig. 7). This stress value characterizes the transition between the fluid state and a new state which may be described as "jammed". The general trend is that critical stress decreases as the solid volume fraction $\phi$ increases (Fig. 8). At very high $\phi(\sim 0.50)$, the fluid phase is no longer observed and it is virtually impossible to separate the gel phase from the jammed phase (in this type of measurement). A significant point is that it is not possible to build a master curve for the liquid-jammed transition. It implies that this transition is not relying on thermal fluctuations but, instead, on the free volume of the dispersion. When taken together, the boundary between the gel state and the fluid state and that between the fluid state and the jammed state represent a dynamic $(\sigma ; \phi)$ phase diagram [32].

\subsection{Steady-State and Fluctuations in Continuous Flow}

When observed in stress-controlled continuous flow experiments, the behavior of silica slurries is qualitatively similar to that of cement slurries but details depend on whether the particle size is in the colloidal domain or not. Figure 9 illustrates the evolution of shear stress as a function of shear rate in stress-controlled experiments, for slurries of $1 \mu \mathrm{m}$ diameter particles at $0.35 \leq \phi \leq 0.50$. A clear transition from a low viscosity fluid regime to a high viscosity jammed regime is observed, provided the solid volume fraction is high enough (in our experimental conditions, above 0.4). The same experiment was performed with 100, 400, 700, 1000,1500 and $2500 \mathrm{~nm}$ spheres, with similar results. In the low shear rate regime, the stress increases according to a power law, $\sigma \propto \dot{\gamma}^{n}$, with $n \leq 1$, which is a signature of weak flocculation. The value of $n$ increases with particle size and reaches 1 with $2.5 \mu \mathrm{m}$ spheres (Fig. 10). This corresponds to Newtonian behavior and shows that flocs of particles of that size, if any, are easily destroyed at the smallest shear rate. It corresponds to the upper limit of the colloidal domain. In the high shear rate regime, the stress increases also according to what seems to be a power law, with $n \gg>1$, but the data are much more scattered than in the low viscosity regime, which suggests that flow instabilities are growing.

The transition between the two regimes was studied in shear rate controlled conditions [32]. When the imposed shear rate is within the stable fluid regime, a well defined stress is measured, with a low amplitude Gaussian noise (Fig. 11). As soon as the jammed regime is reached, much more important fluctuations, which do not belong to the Gaussian statistics, superimpose on this noise. As the imposed shear rate increases and the fluctuations grow, the stress distribution becomes less and less Gaussian and develops a long tail towards high values. Very soon the fluctuations become giant and occasionally reach, at their maximum, a new flow regime of high viscosity. Finally, at still higher flow rate, the system spends most of its time in
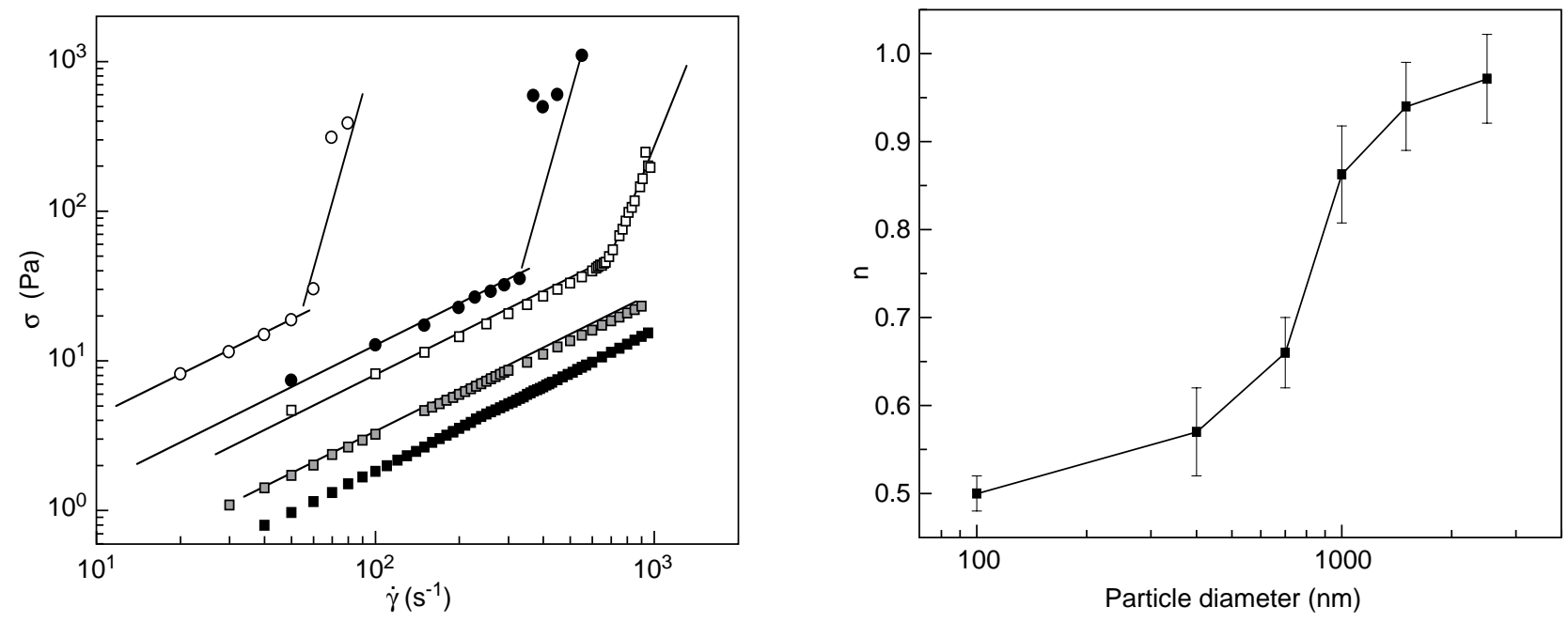

Figure 9

Influence of particle concentration on the evolution of the flow curves $\sigma=f(\dot{\gamma})$ of silica slurries with $1 \mu \mathrm{m}$ particles. The solid volume fraction is, from left to right: $\phi=0.44,0.43$, $0.42,0.40$ and 0.38 , respectively.

Figure 10

Influence of particle size on the shear-thinning exponent measured on silica slurries. 


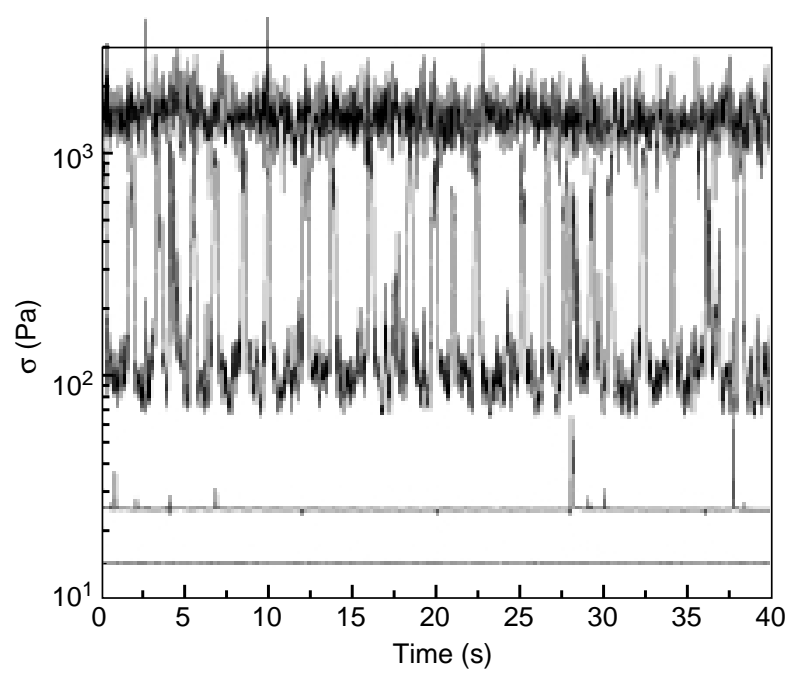

Figure 11

Time evolution of the shear stress for continuous flow of a slurry $(\phi=0.43)$ of $700 \mathrm{~nm}$ silica particles at four imposed shear rates, from bottom to top: $80 \mathrm{~s}^{-1}, 190 \mathrm{~s}^{-1}, 1000 \mathrm{~s}^{-1}$ and $2200 \mathrm{~s}^{-1}$ (right stress scale for the later).

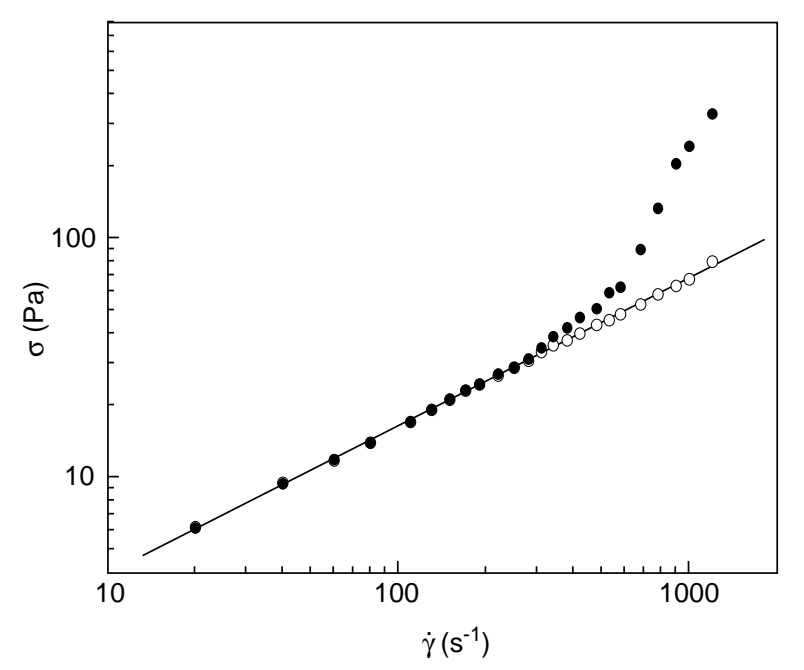

Figure 12

Shear stress $v s$ shear rate for the flow of a slurry $(\phi=0.43)$ of $700 \mathrm{~nm}$ silica particles. Closed symbols are the mean stress values and open symbols are the most probable values, which cannot be distinguished from the average values below $300 \mathrm{~s}^{-1}$. The line is a power law fit of the average values in the liquid regime, leading to $\sigma \propto \dot{\gamma}^{0.63}$. The difference between the filled symbols and the line represents the extra stress stemming from temporary incursion into the jammed regime.

this high viscosity regime and the stress values recover a narrow Gaussian distribution. All along this transition, the two regimes remain clearly distinct and may be separated by measuring the average stress on one hand and the stress with the highest probability on the other hand (Fig. 12).

The simultaneous measurement of the shear stress and the normal effort on the lower plate of a plate-plate geometry in the giant fluctuations regime provides interesting information on the jamming mechanism. As shown in Figure 13, the normal stress difference exhibits fluctuations towards higher values which are, for most of them, remarkably in phase with the shear stress fluctuations [34]. The transient shear-resistant structures which form during flow at high shear rate are also structures which confer to the slurry a dilatant character. However, this does not tell us whether direct interparticle contact is involved or not. The result may still be interpreted either in terms of hollow disordered agglomerates formed by an order-disorder transition or in terms of contact chains along the compressional axis of flow.

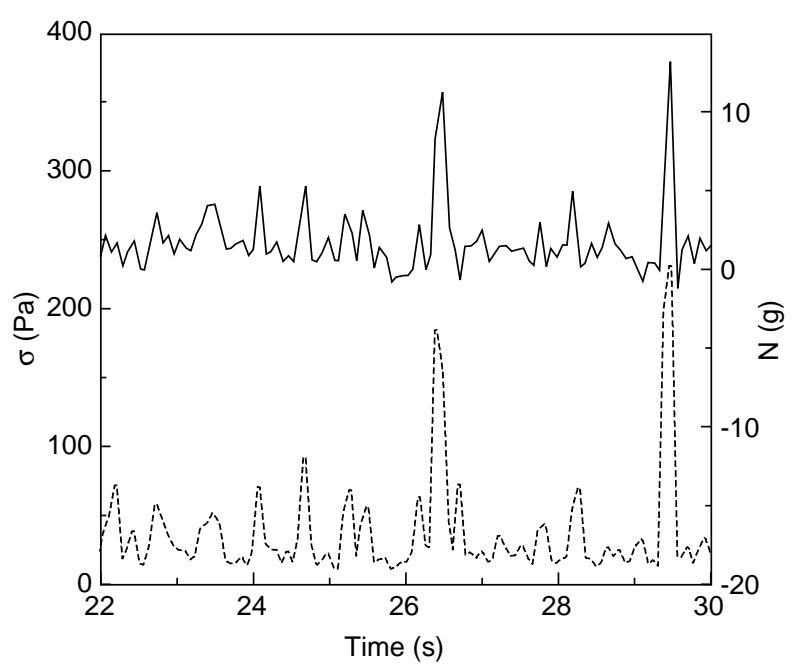

Figure 13

Time evolution of the shear stress (lower curve) and the normal stress difference (upper curve) showing the essentially concomitant character of fluctuations $(2.5 \mu \mathrm{m}$ particles, $\phi=0.44, \dot{\gamma}=50 \mathrm{~s}^{-1}$ ).

In order to clarify this, we prepared silica particles with modified surface states. A first sample of particles was modified by adsorbing a cationic surfactant, didodecyldimethyl ammonium bromide (DDBA), in amounts corresponding to a double layer [34]. This is a typical configuration for lubricating films [35]. A second sample was modified by performing a vigorous basic attack with $\mathrm{NaOH}$. This led to a very rough surface, with an average roughness amplitude of $7 \mathrm{~nm}$, as measured by atomic force microscopy (as compared to less than $1 \mathrm{~nm}$ for the untreated spheres). In terms of tribological properties, as compared to the initial spheres, this should lead to a lower and a higher interparticle friction coefficient respectively. As shown in Figure 14, the shear 


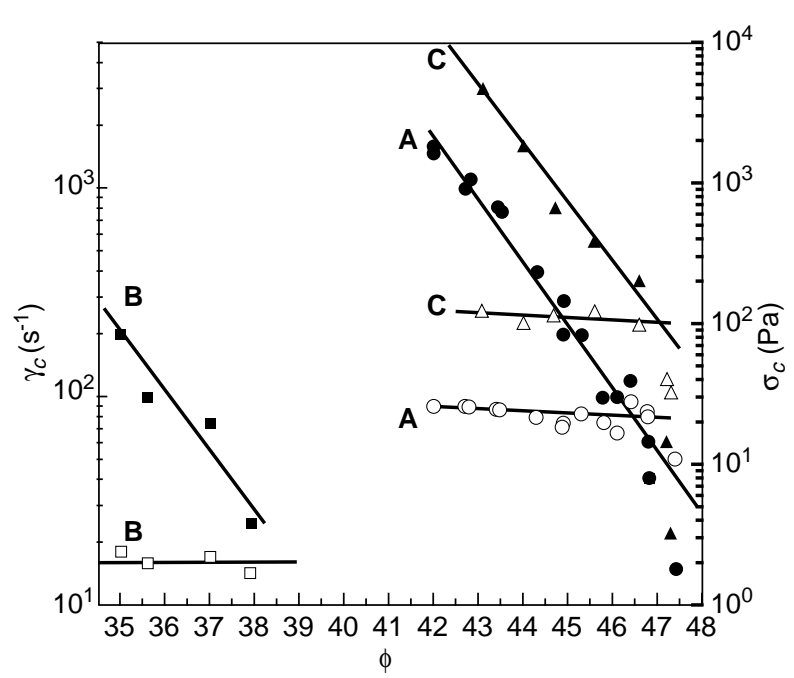

Figure 14

Critical shear stress (closed symbols, right scale) and shear rate (open symbols, left scale) for the jamming transition in slurries of silica particles with different surface states: (A) as obtained after synthesis (middle curve); (B) after $\mathrm{NaOH}$ attack (lower curve); (C) after adsorption of a surfactant (upper curve).

rate for the jamming transition was found to be strongly shifted towards higher values in the former case and to smaller values in the later case. This is a clear indication that jamming is directly controlled by friction and that load bearing direct contact chains are involved. Lubrication makes such chains unstable and removes all load bearing and shear resistant properties. Our result also shows that understanding and controlling jamming requires a precise knowledge of the surface/surface interactions between particles.

\section{SUMMARY AND CONCLUSIONS}

The results reported in this paper illustrate the ambiguous character of cement slurries pointed out in the Introduction. On one hand, the gelation phenomenon, which occurs in the very first minutes after slurry preparation and which is very clearly evidenced by shear modulus measurements in slurries at rest, is a clear illustration of the sensitivity of cement slurries to the noncontact surface forces important in the colloidal world. The shear-thinning character of the gelled slurries under moderate flow rate conditions is a direct consequence of this coagulated structure. As far as experimental techniques are concerned, ultrasonic echo techniques provide a simple way to measure the complex shear modulus of the gel, with an accuracy which seems to be better than with dynamical rheometrical methods.

On the other hand, when totally dispersed by chemical (dispersing agents) and/or hydrodynamic means, cement slurries sheared at high velocity gradients may exhibit another type of structure forming process which is typical of contact forces and hard sphere media. This jamming process, which in rheological terms corresponds to a transition to a high viscosity regime, has been studied in detail in a model dispersion of silica spheres. The transition involves intermittent and increasingly frequent incursions into the highly viscous regime. It was shown to be very dependent on interparticle friction, which is a strong argument in favour of a jamming mechanism involving the formation of load bearing contact chains.

As far as cement slurry formulation is concerned, our work sheds light on the physical parameters which can make the superplasticizer choice and dosage in cement slurries so critical in some cases. A low dosage and/or a superplasticizer with moderate dispersing properties is a guarantee for stability at rest (no sedimentation). However, the viscosity may be too high for easy pumping at low shear rates, but the shear-thinning behavior makes it easier (compared to Newtonian behavior) at high shear rates. The risk for shear-thickening and possibly jamming is low. On the other hand, a high dosage and/or a superplasticizer with strong dispersing properties is a guarantee for a low viscosity at small and moderate shear rates. However, it may lead to sedimentation problems and, at high shear rates, to jamming, unless, as shown in this work, the contacts are efficiently lubricated. These considerations suggest that the formulation of oil well cement slurries should take both the dispersing and the lubricating properties of admixtures into account.

\section{REFERENCES}

1 Flatt, R. (2001) Polymeric Dispersants in Concrete. In: Polymers in Particulate Systems, Hackley, V.A., Somasundaran, P. and Lewis, J.A. Eds., Marcel Dekker, Inc., 247-294.

2 Kendall, K. (1987) Interparticle Friction in Slurries. In: Tribology in Particulate Technology, Briscoe, J. and Adams, J. Eds., Adam Hilger, Bristol and Philadelphia, 91-102.

3 Van Damme, H. (2002) Pastes: Lubricated and Cohesive Granular Media. C.R. Physique, 3, 229-238.

4 Nelson, E.B., Ed. (1990) Well Cementing, Schlumberger Educational Services, Houston.

5 Taylor, H.F.W. (1997) Cement Chemistry, 2nd Ed., Thomas Telford Publishing, London.

6 Van Damme, H. (2002) Colloidal Chemo-Mechanics of Cement Hydrates and Smectite Clays: Cohesion vs swelling. In: Encyclopedia of Surface and Colloid Science, Marcel Dekker, Inc., New York, 1087-1103.

7 Powers, T.C. (1958) Structure and Physical Properties of Hardened Portland Cement Paste. J. Am. Ceram. Soc., 41, 1-6 and references therein.

8 Nachbaur, L., Mutin, J.C., Nonat, A. and Choplin, L. (2001) Dynamic Mode Rheology of Cement and Tricalcium Silicate Pastes from Mixing to Setting. Cem. Concr. Res., 31, 183192. 
9 Jiang, S.P., Mutin, J.C. and Nonat, A. (1995) Studies on the Mechanism and Physico-Chemical Parameters at the Origin of Cement Setting. I. The Fundamental Processes Involved During Cement Setting. Cem. Concr. Res., 25, 779-789.

10 Jiang, S.P., Mutin, J.C. and Nonat, A. (1996) Studies on the Mechanism and Physico-Chemical Parameters at the Origin of Cement Setting. II. Physico-Chemical Parameters Determining the Coagulation Process. Cem. Concr. Res., 26, 491-500.

11 Nachbaur, L., Nkinamubanzi, P.C., Nonat, A. and Mutin, J.C. (1998) Electrokinetic Properties which Control the Coagulation of Silicate Cement Suspensions during Early Age Hydration. J. Coll. Interf. Sci., 202, 261-268.

12 Garrault-Gauffinet, S. and Nonat, A. (1999) Experimental Investigation of Calcium Silicate Hydrate (C-S-H) Nucleation. J. Crystal Growth, 200, 565-574.

13 Nonat, A. (1998) Du gâchage à l'état durci, ce sont les mêmes liaisons qui sont à l'œuvre. Rev. Fr. Genie Civil, 2, 759-765.

14 Maggion, R., Bonnamy, S., Levitz, P. and Van Damme, H. (1996) A Scaling Model of the Microstructural Evolution in $\mathrm{C}_{3}$ S/C-S-H Pastes. In: The Modeling of Microstructure and its Potential for Studying Transport Properties and Durability, Jennings, H., Kropp, J. and Scrivener, K. Eds.; NATO ASI Series E: Applied Sciences, 304, Kluwer Academic Publishers, Dordrecht, 137-155.

15 Stöber, W. and Fink, A. (1968) Controlled Growth of Monodisperse Silica Spheres in the Micron Size Range. J. Coll. Interf. Sci., 26, 62-69.

16 Aït-Kadi, A., Marchal, P., Choplin, L., Chrissemant, A. and Bousmina, M. (2002) Quantitative Analysis of Mixer-Type Rheometers Using the Couette Analogy. Can. J. Chem. Eng., 80, 1166-1174.

17 Nonnet, E., Lequeux, N. and Boch, P. (1999) Elastic Properties of High Alumina Cement Castable from Room Temperature to $1600^{\circ}$ C. J. Eur. Ceram. Soc., 19, 1575-1583.

18 Kulmyraev, A. and McClements, D. (2000) High Frequency Dynamic Shear Rheology of Honey. J. Food Eng., 45, 219224.

19 Nachbaur, L., Mutin, J.C., Nonat, A. and Choplin, L. (2001) Dynamic Mode Rheology of Cement and Tricalcium Silicate Pastes from Mixing to Setting. Cem. Concr. Res., 31, 183192.

20 Mansoutre, S., Colombet, P. and Van Damme, H. (1999) Water Retention and Granular Rheological Behavior of Fresh $\mathrm{C}_{3} \mathrm{~S}$ Paste as a Function of Concentration. Cem. Concr. Res., 29, 1441-1453.
21 Cyr, M., Legrand, C. and Mouret, M. (2000) Study of the Shear Thickening Effect of Superplasticizers on the Rheological Behaviour of Cement Pastes Containing or not Mineral Additives. Cem. Concr. Res., 30, 1477-1483.

22 Hoffman, R.L. (1998) Explanations for the Cause of Shear Thickening in Concentrated Colloidal Suspensions. J. Rheol., 42, 111-123.

23 Brady, J.F. and Morris, J.F. (1997) Microstructure of Strongly Sheared Suspensions and its Impact on Rheology and Diffusion. J. Fluid Mech., 348, 103-139.

24 Parsi, F. and Gadala-Maria, F. (1987) Fore-and-aft Asymmetry in a Concentrated Suspension of Solid Spheres. J. Rheol., 31, 725-732.

25 Brady, J.F. and Bossis, G. (1985) The Rheology of Concentrated Suspensions of Spheres in Simple Shear-Flow by Numerical Simulation. J. Fluid Mech., 155, 105-129.

26 Hoffman, R.L. (1972) Discontinuous and Dilatant Viscosity Behavior of Concentrated Suspensions. 1. Observation of a flow instability. Trans. Soc. Rheol., 16, 155-173.

27 Bertrand, E., Bibette, J. and Schmitt, V. (2002) From ShearThickening to Shear-Induced Jamming. Phys. Rev. E, 66, Paper 060401.

28 Cates, M.E., Wittmer, J.P., Bouchaud, J.Ph. and Claudin, Ph. (1998) Jamming, Force Chains and Fragile Matter. Phys. Rev. Lett., 81, 1841-1844.

29 Miller, B., O’Hern, C. and Behringer, R.P. (1996) Stress Fluctuations for Continuously Sheared Granular Materials. Phys. Rev. Lett., 77, 3110-3113.

30 Coppersmith, S.N., Liu, C.H., Majumdar, S., Narayan, O. and Witten, T.A. (1996) Model for Force Fluctuations in Bead Packs. Phys. Rev. E, 53, 4673-4685.

31 Frith, W.J., d'Haene, P., Buscall, R. and Mewis, J. (1996) Shear Thickening in Model Suspensions of Sterically Stabilized Particles. J. Rheol., 40, 531-548.

32 Lootens, D., Van Damme, H. and Hébraud, P. (2003) Giant Stress Fluctuations at the Jamming Transition. Phys. Rev. Lett., 90, Paper 178301-1;4.

33 Russel, W.B., Saville, D.A. and Schowalter, W.R. (1989) Colloidal Dispersions, Cambridge University Press.

34 Lootens, D., Hébraud, P. and Van Damme, H. (2003) Role of Interparticle Friction in Dynamical Jamming, Eur. Phys. J., submitted.

35 Persson, B.N.J. (1998) Sliding Friction, Springer-Verlag, Berlin.

Final manuscript received in January 2004 or distributed for profit or commercial advantage and that copies bear this notice and the full citation on the first page. Copyrights for components of this work owned by others than IFP must be honored. Abstracting with credit is permitted. To copy otherwise, to republish, to post on servers, or to redistribute to lists, requires prior specific permission and/or a fee. Request permission from Documentation, Institut français du pétrole, fax. +33147527078 , or revueogst@ifp.fr. 